\title{
Evaluation of chemical composition and inhibitory effects of Hypochaeris radicata L. extracts on seed germination and growth of Echinochloa crus-galli L.
}

\author{
Men T. Tran*, Tuan T. Nguyen, Ly H. Sam, Khang T. Do, \& Yen D. H. Nguyen \\ College of Natural Sciences, Can Tho University, Can Tho, Vietnam
}

\section{ARTICLE INFO \\ Research Paper \\ Received: May 22, 2019 \\ Revised: August 30, 2019 \\ Accepted: September 20, 2019}

Keywords

Allelopathic

Barnyard-grass

Germination inhibition

Hypochaeris radicata $\mathrm{L}$.

Phenolic acids

\section{*Corresponding author}

Tran Thanh Men

Email: ttmen@ctu.edu.vn

\begin{abstract}
Allelopathy is a common plant-resistance mechanism in nature, this mechanism demonstrates the growth of this plant that may affect the growth and development of other nearby plant species through the production of secondary compounds. In this study, the allelopathic ability of ethanol extracts from Hypochaeris radicata L. on Echinochloa crus-galli L. was investigated in laboratory conditions. The extracts from stems of Hypochaeris radicata $L$. at the concentration of $5 \mathrm{mg} / \mathrm{mL}$ showed highest inhibition $(73.33 \%)$ on seed germination of barnyard-grass (Echinochloa crus-galli L.). In this study, total polyphenol and flavonoids in Hypochaeris radicata L. were determined by spectrophotometry. Polyphenol and flavonoids present in all parts of the Hypochaeris radicata L. were investigated. The highest polyphenol content in leaves was 9.67 $\mathrm{mg} / \mathrm{g}$ extract and the flavonoid content in roots was $29.56 \mathrm{mg} / \mathrm{g}$ extract. Phenolic acids in extracts from leaves, flowers, and roots were identified by HPLC. The results showed the presence of 7 phenolic acids including chlorogenic, syringic, vanillic, synapic, p-coumaric, benzoic and ellagic in the extracts. The findings highlighted that Hypochaeris radicata $\mathrm{L}$. is a wild plant species with great potential for allelochemicals.
\end{abstract}

Cited as: Tran, M. T., Nguyen, T. T., Sam, L. H., Do, K. T., \& Nguyen, Y. D. H. (2019). Evaluation of chemical composition and inhibitory effects of Hypochaeris radicata L. extracts on seed germination and growth of Echinochloa crus-galli L. The Journal of Agriculture and Development $18(5), 18-23$. 


\title{
Đánh giá thành phần hóa học và tác dụng ức chế sự nảy mầm và phát triển của hạt cỏ lồng vực (Echinochloa crus-galli L.) từ cao chiết cây bồ công anh (Hypochaeris radicata $\mathrm{L}$.)
}

\author{
Trần Thanh Mến*, Nguyễn Trọng Tuân, Sầm Hải Lý, Đỗ Tấn Khang \& Nguyễn Đình Hải Yến \\ Khoa Khoa Học Tự Nhiên, Trường Đại Học Cần Thơ, Cần Thơ
}

\section{THÔNG TIN BÀI BÁO}

Bài báo khoa học

Ngày nhận: 22/05/2019

Ngày chỉnh sửa: $30 / 08 / 2019$

Ngày chấp nhận: 20/09/2019

Tù̀ khóa

Bồ công anh

Cỏ lồng vực

Kháng cỏ

Sự ức chế cảm nhiễm

Ức chế nảy mầm

${ }^{*}$ Tác giả liên hệ

Trần Thanh Mến

Email: ttmen@ctu.edu.vn

\section{TÓM TẮT}

Sự ức chế cảm nhiễm (allelopathy) là một cơ chế đối kháng thực vật phổ biến trong tự nhiên, cơ chế này thể hiện khi sự phát triển của loài thực vật này có thể ảnh hưởng đến sự sinh trưởng và phát triển các loài thực vật lân cận thông qua việc sản sinh các hợp chất thứ cấp. Trong nghiên cứu này, khả năng kháng cỏ lồng vực $(\mathrm{CLV})$ của cao chiết ethanol từ cây bồ công anh $(\mathrm{BCA})$ được khảo sát trong điều kiện phòng thí nghiệm. Kết quả khảo sát cho thấy, tại nồng độ $5 \mathrm{mg} / \mathrm{mL}$ cao chiết của thân $\mathrm{BCA}$ có tác dụng ức chế nảy mầm hạt $\mathrm{CLV}$ cao nhất là $73,3 \%$. Bên cạnh đó, hàm lượng polyphenol và flavonoid tổng số trong cây $\mathrm{BCA}$ được xác định bằng phương pháp đo quang phổ. Các hợp chất polyphenol và flavonoid có trong tất cả các bộ phận của cây được khảo sát. Hàm lượng polyphenol cao nhất trong lá là $9,67 \mathrm{mg} / \mathrm{mL}$ cao, flavonoid có hàm lượng nhiều nhất trong rễ là $29,56 \mathrm{mg} / \mathrm{mL}$ cao. Mẫu cao chiết từ các bộ phận cây $\mathrm{BCA}$ cũng được sử dụng để định tính các acid phenolic bằng phương pháp HPLC. Có bảy loại acid phenolic hiện diện trong các mẫu cao chiết $\mathrm{BCA}$, đó là chlorogenic, syringic, vanillic, synapic, $\mathrm{p}$-coumaric, benzoic và ellagic. Từ các số liệu cho thấy BCA là một loài thực vật hoang dại rất có tiềm năng trong nghiên cứu về các hợp chất tự nhiên có hoạt tính kháng cỏ.

\section{1. Đặt Vấn Đề}

Cỏ dại được xem là một trong bốn nhóm dịch hại nguy hiểm nhất trên ruộng lúa, cùng với sâu hại, bệnh hại và chuột. Các số liệu thống kê cho thấy cỏ dại gây thiệt hại về năng suất lúa cao hơn nhiều so với côn trùng và sâu bệnh (Khang \& ctv., 2016). Đã có nhiều biện pháp phòng trừ cỏ dại đã được áp dụng, trong đó phổ biến nhất là dùng thuốc diệt cỏ hóa học. Bên cạnh hiệu quả tích cực do thuộc diệt cỏ hóa học mang lại thì việc sử dụng quá mức các loại thuốc này đã dẫn đến những tác động tiêu cực cho con người và các hệ sinh thái (Chung \& ctv., 2006). Ức chế cảm nhiễm (allelopathy) là hiện tượng phổ biến trong tự nhiên, hiện tượng này được hiểu là sự phát triển một loài thực vật này đôi khi ảnh hưởng dến sự phát triển của những loài thực vật khác sống lân cận, thông qua việc sản xuất ra các hợp chất thứ cấp được gọi là các chất đối kháng sinh học (allelochemical). Các chất đối kháng này có thể làm hạn chế sự sinh trưởng và phát triển hay thậm chí tiêu diệt một số loài khác trong cùng khu vực (Thi \& ctv., 2014). Các nhà khoa học trên thế giới đã dựa vào hiện tượng này để nghiên cứu và tìm ra các hợp chất kháng cỏ có nguồn gốc tự nhiên vừa có hiệu quả kháng cỏ, vừa thân thiện với môi trường. Các nghiên cứu cho rằng hợp chất có hoạt tính kháng cỏ thường có trong các loài thực vật hoang dại, xâm lấn (Ilori \& ctv., 2010; Khang \& ctv., 2016). Cây bồ công anh (BCA) có tên khoa học Hypochaeris radicata L., đây là một loài thực vật hoang dại thuộc họ Cúc. BCA là loài cỏ có nguồn gốc từ Châu Âu, sau đó phát tán đến các nước khác như Úc, New Zealand, Hàn Quốc, Nhật Bản và Việt Nam. Kim \& ctv. (2005) đã xác định rễ và lá của $\mathrm{BCA}$ có các acid phenolic, các hợp chất này cũng đã được chứng minh là có hoạt tính kháng cỏ. Dù vậy, các số liệu về tác dụng kháng cỏ của $\mathrm{BCA}$ chưa được công bố rõ 
ràng và cụ thể. Nghiên cứu này nhằm mục tiêu đánh giá tiềm năng kháng cỏ lồng vực (CLV) của các cao chiết và xác định các hợp chất hoá học có trong các mẫu cao chiết BCA mọc tại Việt Nam.

\section{Vật Liệu và Phương Pháp Nghiên Cứu}

\subsection{Hóa chất và vật liệu thí nghiệm}

Các hóa chất được sử dụng trong thí nghiệm: Methanol, ethanol, Na2SO4, Quercetin, $\mathrm{AlCl}_{3}$, acid gallic, $\mathrm{Na}_{2} \mathrm{CO}_{3}, \mathrm{NaNO}_{2}, \mathrm{NaOH}$ (Trung Quốc), quercetin, Folin-Ciocalteu (Merck), acid acetic (Việt Nam), các acid phenolic chuẩn: chlorogenic, syringic, vanillic, synapic, p-coumaric, benzoic và ellagic (Trung Quốc).

Mẫu cây BCA ở giai đoạn đang có hoa được thu tại Đà Lạt vào tháng $7 / 2017$. Việc định danh mẫu cây BCA được thực hiện bởi tiến sĩ Nguyễn Thị Kim Huê (Bộ môn Sinh học, Khoa Khoa học Tự nhiên, Trường Đại học Cần Thơ) dựa vào đặc điểm hình thái và mẫu được lưu giữ tại Phòng thí nghiệm Thực vật 2, Bộ môn Sinh học, Khoa Khoa học Tự nhiên, Trường Đại học Cần Thơ. Sau khi mang về phòng thí nghiệm, mẫu cây được rửa sạch và để ráo nước trong 6 giờ. Các bộ phận lá, hoa, thân và rễ được sấy khô ở nhiệt độ $50^{\circ} \mathrm{C}$, tán thành bột thô và ngâm với $1 \mathrm{~L}$ dung môi ethanol trong 7 ngày (mỗi loại gồm $250 \mathrm{~g}$ mẫu khô), dung dịch ngâm được lọc để lấy dịch chiết và cô quay để thu được các mẫu cao chiết ethanol.

\subsection{Khảo sát khả năng ức chế nảy mầm và phát triển của các cao chiết trong điều kiện phòng thí nghiệm}

Thí nghiệm khảo sát khả năng ức chế nảy mầm của cao chiết trong điều kiện phòng thí nghiệm được thực hiện theo phương pháp của Thi \& ctv. (2014), các bước được tiến hành như sau:

Chuẩn bị dung dịch thử: Các cao chiết rễ, lá, thân và hoa được chuẩn bị lần lượt ở ba nồng độ khác nhau bằng cách pha với methanol. Giấy lọc whatman được đặt vào các đĩa petri đã chuẩn bị trước. Lần lượt cho $1 \mathrm{~mL}$ cao chiết từ các phần rễ, thân, lá và hoa với các nồng độ $1 ; 2,5$ và 5 $\mathrm{mg} / \mathrm{mL}$ vào đĩa petri $(50 \mathrm{~mm})$. Đặt đĩa trong tủ hút trong 4 giờ để methanol bay hơi hoàn toàn chỉ còn lại cao chiết trên giấy lọc.

Tiến hành thử: Hạt CLV đã nứt nanh được cho vào đĩa có giấy lọc để sẵn như miêu tả ở các bước trên. Các đĩa petri được đặt trong điều kiện đầy đủ ánh sáng, (12 giờ sáng/12 giờ tối; ánh sáng tự nhiên, nhiệt độ $\left.25^{0} \mathrm{C}\right)$. Thí nghiệm đối chứng không sử dụng cao chiết. Mỗi nghiệm thức được lặp lại 3 lần.

Thời gian theo dõi và các chỉ tiêu quan sát: Các chỉ tiêu như: số hạt nảy mầm, chiều dài rễ, chiều dài thân và trọng lượng khô được ghi nhận sau 7 ngày thí nghiệm.

\subsection{Xác định hàm lượng polyphenol và flavonoid tổng số trong các cao}

Phương pháp xác định hàm lượng polyphenol tổng số bằng phương pháp đo quang được thực hiện theo mô tả của Dewanto \& ctv. (2002), quy trình được thực hiện như sau: Lây $500 \mu \mathrm{L}$ dịch cao chiết có nồng độ $1 \mathrm{~g} / \mathrm{mL}$ (pha trong methanol) cho vào tuýp, sau đó thêm $250 \mu \mathrm{L}$ thuốc thử Folin-Ciocalteu đã được pha trước đó, lắc mạnh và để yên trong 5 phút. Thêm tiếp 250 $\mu \mathrm{L}$ dung dịch $\mathrm{Na}_{2} \mathrm{CO}_{3} 10 \%$, lắc đều và ủ trong 30 phút ở nhiệt độ $40^{\circ} \mathrm{C}$. Sau đó các mẫu được tiến hành đo ở bước sóng $765 \mathrm{~nm}$ bằng máy đo quang phổ 96 giếng kết nối phần mềm Multiskan Go (Thermo Scientific, Phần Lan). Hàm lượng polyphenol được xác định dựa vào phương trình đường chuẩn của acid gallic được chuẩn bị từ dãy nồng độ từ $0-12 \mu \mathrm{g} / \mathrm{mL}$.

Hàm lượng flavonoid tổng số được xác định bằng phương pháp đo quang được Zhishen \& ctv. (1999) hiệu chỉnh như sau: Lấy $1 \mathrm{~mL}$ dịch cao chiết có nồng độ $100 \mu \mathrm{g} / \mathrm{mL}$ (pha trong methanol) cho vào tuýp, tiếp tục thêm vào $1 \mathrm{~mL}$ nước cất và $200 \mu \mathrm{L}$ dung dịch $\mathrm{NaNO}_{2} 5 \%$, trộn đều và để yên trong 5 phút. Thêm tiếp vào hỗn hợp dung dịch $200 \mu \mathrm{L} \mathrm{AlCl}{ }_{3} 10 \%$, để yên trong 6 phút. Sau đó $2 \mathrm{~mL} \mathrm{NaOH} 1 \mathrm{M}$ được thêm vào dung dịch, $600 \mu \mathrm{L}$ nước cất được thêm tiếp vào để thể tích cuối trong tuýp có được là $5 \mathrm{~mL}$. Các mẫu được tiến hành đo ở bước sóng $510 \mathrm{~nm}$. Hàm lượng flavonoid được xác định dựa vào phương trình đường chuẩn của quercetin được chuẩn bị từ dãy nồng độ từ $0-100 \mu \mathrm{g} / \mathrm{mL}$.

\section{4. Định tính các acid phenolic bằng phương pháp HPLC}

Các mẫu cao chiết lá, hoa và rễ cây $\mathrm{BCA}$ được sử dụng để xác định sự hiện diện các acid phenolic bằng HPLC (sắc ký lỏng cao áp, High Performance Liquid Chromatography) Shimazu (LC2010AHT) tại Khoa Khoa học Tự nhiên, Trường Đại học Cần Thơ theo mô tả của Khang \& ctv. (2016). Một sô acid phenolic được xác định dựa 
Bảng 1. Tỉ lệ ức chế sự nảy mầm và sinh trưởng của hạt CLV từ các cao chiết $\mathrm{BCA}^{1}$

\begin{tabular}{lcccc}
\hline Nghiệm thức & $\begin{array}{c}\text { Tỉ lệ ức chế nảy } \\
\text { mầm }(\%)\end{array}$ & $\begin{array}{c}\text { Chiều dài rễ } \\
(\mathrm{mm})\end{array}$ & $\begin{array}{c}\text { Chiều dài thân } \\
(\mathrm{mm})\end{array}$ & $\begin{array}{c}\text { Trọng lượng } \\
\text { khôo }(\mathrm{mg})\end{array}$ \\
\hline Đối chứng & 0 & $4,8 \pm 0,52$ & $4,4 \pm 0,44$ & $17,1 \pm 0,002$ \\
Rễ-1 & 26,7 & $4,4 \pm 0,41$ & $4,4 \pm 0,12$ & $14,3 \pm 0,003$ \\
Rễ-2,5 & 40,0 & $3,40,88$ & $3,7 \pm 0,89$ & $10,5 \pm 0,000$ \\
Rễ-5 & 56,7 & $2,0 \pm 0,66$ & $3,0 \pm 0,11$ & $6,1 \pm 0,007$ \\
Hoa-1 & 20,0 & $4,0 \pm 0,61$ & $4,1 \pm 0,40$ & $16,2 \pm 0,002$ \\
Hoa-2,5 & 20,0 & $2,6 \pm 0,32$ & $3,8 \pm 0,76$ & $14,6 \pm 0,004$ \\
Hoa-5 & 60,0 & $1,1 \pm 0,32$ & $2,4 \pm 0,96$ & $5,3 \pm 0,001$ \\
Thân-1 & 23,3 & $4,0 \pm 0,79$ & $4,0 \pm 0,48$ & $12,2 \pm 0,003$ \\
Thân-2,5 & 43,3 & $1,9 \pm 0,93$ & $3,9 \pm 0,22$ & $9,3 \pm 0,003$ \\
Thân-5 & 73,3 & $0,4 \pm 0,04$ & $1,2 \pm 2,98$ & $3,5 \pm 0,003$ \\
Lá-1 & 30,0 & $4,2 \pm 0,82$ & $4,9 \pm 0,57$ & $13,4 \pm 0,003$ \\
Lá-2,5 & 46,7 & $2,7 \pm 0,80$ & $3,9 \pm 0,99$ & $10,7 \pm 0,003$ \\
Lá-5 & 60,0 & $1,5 \pm 0,44$ & $2,7 \pm 0,99$ & $6,7 \pm 0,002$ \\
\hline${ }^{1}$ CLV. Cỏ lồng vực: BCA. Bồ công anh. & & &
\end{tabular}

vào các acid phenolic chuẩn sau: chlorogenic, syringic, vanillic, synapic, $\mathrm{p}$-coumaric, benzoic và ellagic.

\section{Kết Quả và Thảo Luận}

\subsection{Tác dụng ức chế sự nảy mầm và phát triển hạt CLV của cao chiết BCA}

Tác dụng ức chế nảy mầm hạt CLV của các cao chiết cây $\mathrm{BCA}$ được trình bày ở Bảng 1 . Từ kết quả thí nghiệm cho thấy cao chiết từ rễ, hoa, thân và lá của cây $\mathrm{BCA}$ có ảnh hưởng đến nảy mầm và phát triển của CLV trong điều kiện phòng thí nghiệm phụ thuộc vào nồng độ, nồng độ càng cao khả năng ức chế nảy mầm và sự phát triển của CLV càng mạnh, khi so sánh với thí nghiệm đối chứng không sử dụng cao chiết.

Mức độ ức chế CLV tỉ lệ thuận với nồng độ cao chiết. Ở nồng độ $5 \mathrm{mg} / \mathrm{mL}$, cao chiết thân có khả năng ức chế nảy mầm cao nhất $(73,3 \%)$, cao chiết rễ, lá và hoa ức chế hạt CLV nảy mầm từ 56,7 - 60\%. Nghiên cứu của Baličević \& Ravlić (2015) cho thấy hoạt tính ức chế thực vật của cao chiết thân cây cúc la mã (Tripleurospermum inodorum) mạnh hơn cao chiết lá. Nghiên cứu khác của Abu-Romman (2016) thử nghiệm dịch trích của cây Achillea biebersteinii (một loài thực vật thuộc chi cỏ Thi, họ Cúc) trên lúa mạch hoang dại cũng cho thấy, dịch trích thân của Achillea biebersteinii có hoạt tính ức chế sự phát triển của rễ lúa mạch hoang dại cao hơn dịch trích rễ. Trong nghiên cứu này, các nghiệm thức ở nồng độ thấp cho thấy có khả năng ức chế nảy mầm nhưng không mạnh như ở nồng độ $5 \mathrm{mg} / \mathrm{mL}$. Bên cạnh đó, các chỉ tiêu như chiều dài rễ, chiều dài thân và trọng lượng khô của CLV được ghi nhận trong thí nghiệm này cũng bị ảnh hưởng khi xử lý bằng các cao chiết. Đây là các chỉ tiêu thể hiện sự sinh trưởng và phát triển của CLV. Tuy nhiên, sự ảnh hưởng này chỉ khác biệt có ý nghĩa khi được xử lý cao chiết ở nồng độ cao. Ở nồng độ $5 \mathrm{mg} / \mathrm{mL}$, cao chiết từ các bộ phận của cây $\mathrm{BCA}$ có khả năng ức chế sự phát triển của rễ và tích lũy sinh khối của CLV hơn $50 \%$ so với đối chứng không sử dụng cao chiết. Cây BCA là loài thực vật thuộc họ Cúc, một số cây khác thuộc họ Cúc như dã quỳ, hướng dương và cỏ hôi đã được chứng minh là có hoạt tính kháng cỏ dại (Ilori \& ctv., 2010). Từ các số liệu trên có thể cho rằng trong cao chiết từ lá, hoa và rễ cây $\mathrm{BCA}$ có chứa các chất hoặc hợp chất có khả năng kháng cỏ.

\subsection{Hàm lượng polyphenol và flavonoid tổng số}

Kết quả thí nghiệm được trình bày ở Bảng 2 cho thấy hàm lượng polyphenol tổng số có trong $1 \mathrm{~g}$ cao chiết rễ cây $\mathrm{BCA}$ tương đương với 8,67 mg acid gallic, ở hoa là $3,03 \mathrm{mg}$, ở lá là 9,67 $\mathrm{mg}$ và ở thân là $3,5 \mathrm{mg}$. Hàm lượng flavonoid tổng số có trong $1 \mathrm{~g}$ cao chiết rễ, hoa, thân và lá lần lượt là $29,56 \mathrm{mg}, 27,00 \mathrm{mg}, 21,35 \mathrm{mg}$ và $22,64 \mathrm{mg}$. Polyphenol và flavonoid là hai nhóm hợp chất đã được nghiên cứu và chứng minh là có hoạt tính ức chế thực vật (Li \& ctv., 2010; 
Bảng 2. Hàm lượng polyphenol và flavonoid tổng số có trong các cao chiết bồ công anh

\begin{tabular}{lcc}
\hline Cao chiết & $\begin{array}{c}\text { Hàm lượng polyphenol tổng } \\
(\mathrm{mg} / \mathrm{g} \text { cao chiết })^{1}\end{array}$ & $\begin{array}{c}\text { Hàm lượng flavonoid tổng } \\
(\mathrm{mg} / \mathrm{g} \text { cao chiết })^{2}\end{array}$ \\
\hline Rễ & $8,67 \pm 0,429^{\mathrm{a}}$ & $29,56 \pm 2,565^{\mathrm{a}}$ \\
Hoa & $3,03 \pm 0,093^{\mathrm{b}}$ & $27,00 \pm 0,237^{\mathrm{ab}}$ \\
Thân & $3,50 \pm 0,446^{\mathrm{b}}$ & $21,35 \pm 0,311^{\mathrm{c}}$ \\
Lá & $9,67 \pm 0,244^{\mathrm{a}}$ & $22,64 \pm 0,573^{\mathrm{bc}}$ \\
\hline${ }^{1}$ Các giá trị trong cột này được xác định dựa vào phương trình đường chuẩn của acid gallic $(\mathrm{y}=0,084 \mathrm{x}$ \\
${ }^{+}$0,0411, $\left.\mathrm{r}^{2}=0,9987\right)$. \\
${ }^{2}$ Các giá trị trong cột này được xác định dựa vào phương trình đường chuẩn của quercetin $(\mathrm{y}=0,0568 \mathrm{x}$ \\
-0,0149, $\left.\mathrm{r}^{2}=0,9969\right)$. \\
Sồ liệu là giá trị trung bình của ba lần lặp lại. \\
a-c Các số có chữ cái theo sau trong cùng một cột giống nhau thì khác biệt không ý nghĩa $5 \%$ bằng phép \\
thử Tukey.
\end{tabular}

Weston \& Mathesius, 2013). Trong một khảo sát của Pejman \& ctv. (2011) cho thấy, chiết xuất từ cây hoa hướng dương Helianthus annuus L. (thuộc họ Cúc) có hoạt tính đối kháng ức chế sự nảy mầm và phát triển các loại hạt như Amaranthus retroflexus, Portulaca oleracea, Lolium rigidum, Hordeum spontaneum, Triticum aestivum và Carthamus tinctorius. Bên cạnh đó nghiên cứu này cũng cho rằng tác nhân gây hiện tực ức chế sự nảy mầm và phát triển của hạt chính là polyphenol và flavonoid (Pejman \& ctv., 2011). Tứ đó cho thấy, các chiết xuất ethanol từ cây $\mathrm{BCA}$ có thể có chứa các nhóm chất có hoạt tính kháng thực vật. Hoạt tính này có được có thể là do có sự hiện diện của nhóm chất polyphenol và flavonoid.

\subsection{Kết quả định tính acid phenolic bằng HPLC trong cao}

Kết quả thí nghiệm định tính cho thây, có bảy loại acid phenolic được phát hiện trong các cao chiết từ cây $\mathrm{BCA}$, đó là chlorogenic, syringic, vanillic, synapic, $\mathrm{p}$-coumaric, benzoic và ellagic. Trong đó, ellagic và chlorogenic là hai acid phenolic có hiện diện ở cả lá, hoa và rễ $\mathrm{BCA}$. Wang \& ctv. (2017) cho rằng các acid phenolic như chlorogenic, benzoic và p-coumaric có hoạt tính kháng cỏ đuôi trâu (Festuca arundinace) và kháng cây cao lương (Sorghum sudanense). Một khảo sát khác của Jabran (2017) chứng minh syringic và vanillic là hai acid phenolic có hoạt tính kháng cỏ. Acid synapic cũng đã được Xuan \& ctv. (2003) xếp vào nhóm chất có khả năng kháng cỏ dại. Đáng lưu ý trong nghiên cứu này là acid ellagic, đây là acid phenolic có hiện diện nhiều ở cả lá, hoa và rễ của cây $\mathrm{BCA}$, đã được chứng minh có khả năng ức chế sự nảy mầm hạt sà lách (Latuca sativa L.) (Cameron \& Julian, 1980). Như vậy, có thể thấy rằng bảy loại acid phenolic được phát hiện có trong cây $\mathrm{BCA}$ của nghiên cứu này dều được chứng minh là có hoạt tính kháng lại một số loài thực vật khác từ các công trình nghiên cứu trước đây. Do đó kết quả của nghiên cứu này cho thấy rằng cây $\mathrm{BCA}$ mọc ở Việt Nam có khả năng tổng hợp các hợp chất thứ cấp có hoạt tính kháng cỏ.

\section{Kết Luận}

Cao chiết BCA có khả năng ức chế tương đối mạnh sự nảy mầm và phát triển của hạt CLV ở nồng độ $5 \mathrm{mg} / \mathrm{mL}$ với phần trăm ức chế tối đa là $73,3 \%$. Kết quả định lượng cho thấy hàm lượng polyphenol có trong lá, hoa, thân và rễ của cây BCA lần lượt là $9,67 \pm 0,244 ; 3,03 \pm 0,093 ; 3,50$ $\pm 0,446$ và $8,67 \pm 0,429 \mathrm{mg} / \mathrm{g}$ cao chiết. Hàm lượng flavonoid có trong lá, hoa, thân và rễ của cây BCA lần lượt là $22,64 \pm 0,573,27,00 \pm 0,237$; $21,35 \pm 0,311$ và $29,56 \pm 2,565 \mathrm{mg} / \mathrm{g}$ cao chiết. Có bảy loại acid phenolic có hoạt tính kháng cỏ dại được phát hiện có trong cây BCA thu hái tại Đà Lạt bằng phương pháp HPLC, đó là chlorogenic, syringic, vanillic, synapic, $\mathrm{p}$-coumaric, benzoic và ellagic. Từ những kết quả trên cho thấy cây BCA mọc tại Đà Lạt là một loài thực vật hoang dại có khả năng tổng hợp các các chất có hoạt tính kháng cỏ. Đây là một loài thực vật có nhiều tiềm năng để nghiên cứu các hợp chất kháng cỏ dại có nguồn gốc tự nhiên.

\section{Tài Liệu Tham Khảo (References)}

Abu-Romman, S. (2016). Differential allelopathic expression of different plant parts of Achillea biebersteinit. Acta Biologica Hungarica 67(2), 159-168.

Baličević, R., \& Ravlić, M. (2015). Allelopathic effect 
of scentless mayweed extracts on carrot. Herbologia $15(1), 11-18$.

Cameron, H. J., \& Julian, G. R. (1980). Inhibition of protein synthesis in lettuce (Latuca sativa L.) by allelopathic compounds. Journal of Chemical Ecology 6(6), 989-995.

Chung, I. M., Kim, J. T., \& Kim, S. H. (2006). Evaluation of allelopathic potential and quantification of momilactone A, B from rice hull extracts and assessment of inhibitory bioactivity on paddy field weeds. Journal of Agricultural and Food Chemistry 54(7), 2527-2536.

Dewanto, V., Xianzhong, W., Adom, K. K., \& Liu, R. H. (2002). Thermal processing enhances the nutritional value of tomatoes by increasing total antioxidant activity. Journal of Agricultural and Food Chemistry 50(10), 3010-3014.

Ilori, O. J., Otusanya, O. O., Adelusi, A. A., \& Sanni, R. O. (2010). Allelopathic activities of some weeds in the Asteraceae family. International Journal of Botany 6(2), 161-163.

Jabran, K. (2017). Manipulation of allelopathic crops for weed control. Springer briefs in plant science Switzerland. Berlin, Germany: Springer.

Khang, D. T., Anh, L. H., Ha, P. T. T., Tuyen, P. T., Quan N. V., Minh, L. T., Quan N.T., Minh, T. N., Xuan, T.D., Khanh, T. D., \& Trung, K. H. (2016). Allelopathic activity of dehulled rice and its allelochemicals on weed germination. International Letters of Natural Sciences 58(2), 1-10.

Kim, O. Y., Park, S. I., Jung, I. M., \& Ha, S. Y. (2005). The allelopathic effects of aqueous extracts of Hypochaeris radicata L. on forage crops. Journal of Life Science 15(6), 871-878.
Li, Z. H., Qiang W., Xiao R., Cun-De P., \& De-An J. (2010). Phenolics and plant allelopathy. Molecules 15 , 8933-8952.

Pejman, N., Hassan, K., Morteza, M., \& Nayereh, A. S. H. (2011). Allelopathic potential of sunflower on weed management in safflower and wheat. Australian Journal of Crop Science 5(11), 1434-1440.

Thi, H. L., Lin, C. H., Smeda, R. J., Leigh, N. D., Wycoff, W. G., \& Fritschi, F. B. (2014). Isolation and identification of an allelopathic phenylethylamine in rice. Phytochemistry 108, 109-121.

Wang, R. L., Liu, S. W., Xin, X. W., Chen, S., Peng, G. X., Su, Y. J., \& Song, Z. K. (2017). Phenolic acids contents and allelopathic potential of 10-cultivars of Alfalfa and their bioactivity. Allelopathy Journal 40(1), 63-70.

Weston, L. A., \& Mathesius, U. (2013). Flavonoids: their structure, biosynthesis and role in the rhizosphere, including allelopathy. Journal of Chemical Ecology $39(2), 283-297$.

Xuan, T. D., Tsuzuki, E., Terao, H., Matsuo, M., Khanh, T. D., Murayama, S., \& Hong, N. H. (2003). Alfalfa, rice by-products and their incorporation for weed control in rice. Weed Biology and Management 3(2), 137144.

Zhishen, J., Mengcheng, T., \& Jianming, W. (1999). The determination of flavonoid contents in mulberry and their scavenging effects on superoxide radicals. Food Chemistry 64(4), 555-559. 